NASA Technical Memorandum 100291

\title{
Fatigue Life Prediction Modeling for Turbine Hot Section Materials
}

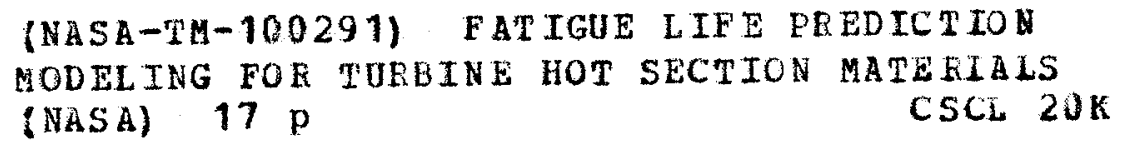

G.R. Halford

Lewis Research Center

Cleveland, Ohio

and

T.G. Meyer, R.S. Nelson, D.M. Nissley, and G.A. Swanson

United Technologies

East Hartford, Connecticut

Prepared for the

33rd International Gas Turbine and Aeroengine Congress and Exposition sponsored by the American Society of Mechanical Engineers

Amsterdam, The Netherlands, June 5-9, 1988 


\title{
ORIGINAL PAGE IS OF POOR QUALTTY
}

\section{FATIGUE LIFE PREDICTION MODELING FOR TURBINE HOT SECTION MATERIALS}

\author{
G.R. Halford \\ National Aeronautics and Space Administration \\ Lewis Research Center \\ Cleveland, Ohio 44135 \\ T.G. Meyer, R.S. Nelson, D.M. Nissley, and G.A. Swanson \\ United Technologies \\ Pratt \& Whitney \\ East Hartford, Connecticut 06108
}

\section{ABSTRACT}

This paper presents a summary of the life prediction methods developed under the NASA Lewis Research Center's Hot Section Technology (HOST) program. A major objective of the fatigue and fracture efforts under the HOST program was to significantly improve $\stackrel{g}{m}$ the analytic life prediction tools used by the aero' nautical gas turbine engine industry. This has been achieved in the areas of high-temperature thermal and mechanical fatigue of bare and coated high-temperature superalloys. Such technical improvements will eventually reduce life cycle costs.

The cyclic crack initiation and propagation resistance of nominally isotropic polycrystalline alloys and highly anisotropic single crystal alloys has been addressed. A sizeable data base has been generated for three alloys [cast PWA 1455 (B-1900+ Hf), wrought Inconel 718 , and cast single crystal PWA 1480] in bare and coated conditions. Two coatings systems, diffusion aluminide (PWA 273) and plasma sprayed MCrAlY overlay (PWA 286) were employed.

Life prediction modeling efforts were devoted to creep-fatigue interaction, oxidation, coatings interactions, multiaxiality of stress-strain states, mean stress effects, cumulative damage, and thermomechanical fatigue. The fatigue crack initiation life models developed to date include the Cyclic Damage Accumulation (CDA) Model of Pratt \& Whitney and the Total Strain Version of Strainrange Partitioning (TS-SRP) of NASA Lewis for nominally isotropic materials, and the Tensile Hysteretic Energy Model of Pratt \& Whitney for anisotropic superalloys. The fatigue model being developed by the General Electric Company is based upon the concepts of Path-Independent Integrals (PII) for describing cyclic crack growth under complex nonlinear response at the crack tip due to thermomechanical loading conditions. A micromechanistic oxidation crack extension model has been derived by researchers at Syracuse University. The models are described and discussed in the paper. Only limited verification has been achieved to-date as several of the technical programs are still in progress and the verification tasks are scheduled, quite naturally, near the conclusion of the program.
To-date, efforts have concentrated on development of independent models for cyclic constitutive behavior, cyclic crack initiation, and cyclic crack propagation. The transition between crack initiation and crack propagation has not been thoroughly researched as yet, and the integration of these models into a unified life prediction method has not been addressed.

\section{INTRODUCTION}

\section{3ackground}

Life cycle costs ranging from initial design costs to field replacement costs of 1 imited durability component parts are the driving elements for improved analytic life prediction capability. Since life cycle costs are the highest for hot section gas turbine engine components, our efforts have concentrated on the problems in this area. Accurate calculation of expected service lifetimes, is crucial to the final judgment to proceed with a particular design. Inaccurate life calculations result in overly expensive designs--either from an under utilization of potential or a lack of adequate life. The fatigue and fracture portion of the HOST program was initiated to reduce life cycle costs through improved accuracy of analytic life predictive models. The specific areas of primary concern are very high-temperature cyclic crack initiation and propagation in both isotropic and anisotropic superalloys used in hot section turbine engine components.

\section{HOST Life Prediction Program}

Table I lists the specific programs that have supported the fatigue and fracture life prediction efforts. Each will be discussed and the most significant of the numerous accomplishments will be pointed out. Space does not permit elaboration of the numerous methods nor of the experimental details. The reader is referred to the more thoroughly documented original references. 
In addition to the Industrial Contracts and University Grants supported by the the HOST program, some funding was set aside to rejuvenate aging test facilities in the the area of fatigue and fracture. The advanced, high-temperature fatigue and structures research laboratory at Lewis is now operational, and in fact has grown to the point of requiring further expansion. The facility is equipped with the very latest closed-loop, servo-controlled machinery, and most importantly boasts a unique computerized nerve center for programmed test control; data taking, storage and retrieval; and data reduction and plotting.

\section{ISOTROPIC MATERIAL MODELING}

\section{Cyclic crack Initiation}

The majority of usable cyclic lifetime of turbine ngine hot section components is usually spent in what : s called the "cyclic crack initiation" portion of the fatigue life. Strictiy speaking, crack initiation does indeed contain a considerable amount of cyclic crack growth, although the physical size of the cracks is quite small. From an engineering point of view, any crack growth below a crack size of approximately $0.8 \mathrm{~mm}$ ( $1 / 32 \mathrm{in.}$ ) typically is included in the "initiation" portion of the life. Justification for this definition is based upon: (a) the inability to reliably detect cracks of smaller size, and (b) the inability of cyclic crack growth laws to adequately model cyclic extension of cracks smaller than this size. Such a definition of cyclic crack initiation is used in the development of the Pratt \& Whitney Cyclic Damage Accumulation Model addressed in the next section.

Pratt \& Whitney Cyclic Damage Accumulation (CDA) model. The interaction of creep with fatigue at high temperatures is being studied in detail under NASA/HOST Contract NAS3-23288, "Creep-Fatigue Life Prediction for Engine Hot Section Materials (Isotropic)" (Moreno, 1983, Moreno et al., 1986, and Nelson et al., 1986). This effort has investigated fundamental approaches to high temperature crack initiation life prediction using a cast nickel-base alloy, PWA 1455 ( $81900+H f)$ as the base material. During the program, over 157 specimen tests were completed under loading conditions which consisted of monotonic tensile and creep tests as well as continuously cycled fatigue tests. A review of existing fatigue models was conducted, and desirable features of each of these were identified. A new method of high temperature fatigue life prediction called Cyclic Damage Accumulation (CDA) was subsequently developed which incorporates many of these features.

Complex loadings were introduced during the latter stages of the program to study the effects of thermomechanical fatigue, multiaxial loading, cumulative damage, environment, mean stress, and coatings. An additional 160 strain-controlled fatigue tests have been conducted as a part of these tasks. Three different surface treatments were utilized for the TMF and coated tests: bare (no coating), overlay NiCoCrAlY coated, and diffusion aluminide coated. Several refinements have been incorporated into the CDA life prediction model based on the results of these complex tests. The current form of the model for accumulated transigranular damage is given by $\mathrm{Eq}$. (1).

$$
=\int_{0}^{N} i\left(\frac{1}{\varepsilon_{p}}\right)\left(\frac{1}{G_{N L}}\right)\left(\frac{d D}{d N}\right)_{R}\left[\left(\frac{\Delta \sigma}{\Delta \sigma_{R}}\right)\left(\frac{\sigma_{T}}{\sigma_{T R}}\right)+D_{T D}\left(\frac{f_{O X}}{f_{O X}}\right)\right] d N
$$

where

$N_{i}$ initiation life, transgranular mode

$\bar{\varepsilon}_{p} \quad$ primary creep ductility

GNL nonlinear damage accumulation function

$\left(\frac{d D}{d N}\right)_{R}$ reference cyclic damage rate

$\sigma_{\mathrm{T}}$ maximum tensile stress in current cycle

oTR reference maximum tensile stress

$\Delta o$ stress range of current cycle

$\Delta \sigma_{R} \quad$ reference stress range

DT $_{\text {J }}$ time-dependent damage rate modifier

fox cyclic oxidation rate for current fatigue cycle

foxR reference fatigue/cyclic oxidation rate

The basis for Eq. (I) is explained by Moreno (1983), Moreno et al. (1984), and Nelson (1986). A goal of the program to develop the CDA model was to limit the complexity of the experiments to determine the material behavior constants. For example, only monotonic creep tests and continuous cycling fatigue experiments are required to evaluate the constants in the first term of the CDA expression. The second term requires that cyclic oxidation measurements be made during fatigue testing.

Nonlinear damage accumulation calculations are now possible for both cycle-dependent and timedependent, cases. Modular terms which capture the effects of multiaxiality, coatings, and intergranular cracking are currently under development. The ability of the model to correlate thermomechanical fatigue data is shown in Fig. I for bare and coated material, respectively. Complete details of test conditions employed are given by Nelson (1986). Most of the thermomechanical fatigue (TMF) tests were performed at temperatures between 538 and $871{ }^{\circ} \mathrm{C}$ at one $\mathrm{CPM}$ with total mechanical strain ranges between 0.4 and 0.5 percent. The dog-leg experiments utilized $54 \mathrm{sec}$ hold periods in either tension or compression. Work continues on a refined version of the model which will attempt to capture all the important life trends seen during the latter stages of the contract.

The final task under the program is to perform a similar series of tests on an alternate alloy, wrought Inconel 718. A total of 55 of these specimen tests have now been completed, including isothermal, thermomechanical fatigue, and multiaxial strain-controlled tests. It is expected that the final form of the CDA model may include additional refinements required to predict properly the life trends for forged alloys.

Lewis Research Center Total Strain Version of Strainrange Partitioning. The Strainrange Partitioning (SRP) method for characterizing and predicting creepfatigue behavior of alloys has long been associated with using inelastic strains to relate to cyclic life. Recent advances by Halford and Saltsman (1983) and Saltsman and Halford (1985) now permit the approach to be expressed in terms of total strain range versus cyclic life. These developments make the SRP method more attractive for application to life prediction of aeronautical gas turbine hot section components. 
Here, materials and loading conditions result in strain levels that, while they are severe and produce low-cycle fatigue cracking, involve only small amounts of inelastic deformation within nominally elastic strain fields. The limited inelasticity produced locally may exert a significant influence on life. The type of inelastic strains present (timedependent creep and time-independent plasticity) and the direction of the strains (tension or compression) can be quite important in governing the resultant cyclic crack initiation life. The total strain based SRP approach (TS-SRP) has been developed to deal explicitly with the above conditions. A brief description is given below to show how the procedures are employed.

The total strain range, $\Delta \varepsilon_{t}$, is the sum of two terms, the elastic, $\Delta \varepsilon_{e l}$, and the inelastic, $\Delta \varepsilon_{i n}$, strain ranges. Each strain range is related to cyclic iffe by a power law relation as shown in Eq. (1) and Fig. 2 .

$$
\Delta \varepsilon_{t}=\Delta \varepsilon_{e l}+\Delta \varepsilon_{i n}=B\left(N_{f}\right)^{b}+C^{\prime}\left(N_{f}\right)^{c}
$$

To apply Eq. (2) at high temperatures requires the evaluation of the coefficients, $B$ and $C^{\prime}$, and the exponents, $b$ and $c$. It is assumed, initially, that $b$ and $c$ are constants for all conditions at a given temperature, i.e., they are time- and waveshapeindependent, and that $B$ and $C^{\prime}$ are time- and cycle waveshape-dependent.

To determine $C^{\prime}$, as many of the four basic SRP inelastic strain range versus life relations, PP, CC, $P C$, and $C P$, as are required for the cycle of interest must be known. How the inelastic strains are partitioned within the cycle must also be known, i.e., how much of each type of PP, CC, PC, or CP strain range is present in the hysteresis loop. Experimental procedures for establishing the four inelastic SRP life relations, techniques for approximating them, and experimental partitioning procedures are given by Hirschberg and Halford (1976), Halford et al. (1977), and Manson et al. (1975), respectively.

In principle, the partitioning and thus the determination of ' $C$ ' could be accomplished analytically using advanced cyclic constitutive equations such as those developed under the NASA/HOST Program by Lindholm (1984) and Ramaswamy et a 1. (1985). Advanced cyclic constitutive models are capable of computing the exact details of a stress-strain hysteresis loop. knowing only the imposed temperature, total mechanical strains, and how they vary with time for a representative cycle. Details of the inelastic straining rates are also computable, and hence creep strains (timedependent) and plastic strains (time-independent) can be separated, i.e., partitioned. If a constitutive model is not available, the empirical approach presented by Saltsman and Halford (1988) can be used to determine $C^{\prime}$ and $B$. The required equations are summarized below.

$$
\begin{gathered}
C^{\prime}=\left[\sum F_{i j}\left(C_{i j}\right)^{1 / c}\right] c \\
B=K_{i j}\left(C^{\prime}\right)^{n} \\
F_{i j} /\left(\Delta \varepsilon_{t}\right)^{\alpha}=A(t)^{m} \\
K_{i j}=A_{i}(t)^{m_{i}}
\end{gathered}
$$

where $\quad i j=p p, c c, p c$, or $c p$

The cyclic strain hardening exponent, $n$, in Eq. (4) is obtained from completely reversed rapid strain-cycling PP results,

$$
\Delta \varepsilon_{e l, p p}=K_{p p}\left(\Delta \varepsilon_{p p}\right)^{n}
$$

For cycles involving creep,

$$
\Delta \varepsilon_{e l, i j}=K_{i j}\left(\Delta \varepsilon_{i j}\right)^{n}
$$

A complete nomenclature for TS-SRP is given by Saltsman (1988).

To apply the TS-SRP approach, the specific mission cycles of interest are identified and the cyclic stress-strain-temperature-time history is determined at the critical location in the structural component. Then, the appropriate elastic and inelastic strain range versus life relations are calculated and added together to obtain the desired total strain range versus cyclic life diagram. Entering the diagram with the known total strain range, the cyclic life is determined directly without having to calculate the magnitude of the inelastic strain range. Example life prediction calculations by the TS-SRP approach have been reported by Halford and Saltsman (1983), Moreno et al. (1985), and Saltsman and Halford (1988). The degree of success of the method is shown in Fig. 3. Here, the TS-SRP method was applied by Moreno et al. (1985) to a series of five different types of complex verification experiments performed on the nickel-base superalloy, B1900+ Hf. A direct comparison of the TS-SRP approach with the CDA model also was made by Moreno et al. (1985), wherein the principal features of each method were emphasized. The TS-SRP model and the Pratt \& Whitney CDA model were both designed for application to strain-driven fatigue loading conditions in the nominally elastic regime. Both methods are currently being adapted for application to TMF problems.

\section{Cyclic Crack Propagation}

Cyclic growth of cracks and defects in turbine engine hot section components is of considerable concern because of the lack of structural redundancy in the construction of these components. As such, crack growth to a critical fracture size must by avoided to prevent catastrophic fast fracture and subsequent loss of engine function. Typically, concern for fast fracture is associated more with rotating components than with static structures. For combustor liners, guide vanes, stationary spacers, and other nonrotating components, concern for cyclic crack growth is more economic in nature than safety-related. In the HOST fatigue and fracture program, two approaches to crack growth were taken. An engineering methodology was applied in an attempt to develop directly useful design tools, and a scientific approach examined the micromechanisms of crack extension at the crystallographic level and the interaction with oxidation phenomena.

General Electric Path-Independent Integral model. A major goal of the contract program with the General Electric Company is to develop reliable and accurate engineering life prediction capabilities to deal with cyclic crack growth at elevated temperatures. Several of the Path-Independent Integrals, Jx, that have been proposed over the past few years have been shown to be 
applicable to fracture mechanics calculations of cyclic crack growth under uniform and nonuniform thermal gradients and thermomechanical loadings. Specifically, the various $J x$ integrals proposed by Tada et al. (1973), Ainsworth et al. (1978), Blackburn et al. (1977), Kishimoto et al. (1980), and Atluri (1982) have been found suitable for analysis of crack stress fields involving nonlinear and time-dependent thermomechanical response (Kim and Orange, 1988). The traditional Rice J-integral (Rice, 1968), however, becomes path dependent and loses its physical significance for thermomechanical loadings. Figure 5 compares the results of a series of calculations applied to an instrumented single edge notch specimen of Incone) 718 with a linear thermal gradient. The current program with the General Electric Company will continue into 1989, during which time one of the pathindependent integrals will be selected for further verification under realistic thermomechanical loading conditions found in the hot section of gas turbine engines.

Syracuse University oxidation crack extension model. Liu and Oshida (1986) and Oshida and Liu (1988) have taken a micromechanistic approach to dealing with crack propagation in superalloys. A model of intermittent micro-rupture of grain boundary oxide has been proposed for high temperature fatigue crack extension. The model is outlined briefly below for the case of a trapezoidal waveform.

Oxygen arriving at a grain boundary crack tip must diffuse into the region ahead of the crack in order to form oxide along the grain boundary. When the crack tip grain boundary oxide, at a given stress level, reaches a critical size, $\delta a$, the oxide will rupture and the crack will grow by the amount, $\delta$. The critical size, $\delta a$, depends on the stress intensity level during the holding period. Once the crack tip has advanced to its new position, the process of grain boundary diffusion, grain boundary oxidation, and micro-rupture of the oxide is repeated. This process of micro-rupture of a crack tip grain boundary can recur intermittently during a fatigue cycle, and in fact, many micro-ruptures can take place. After each micro-rupture, the penetration of grain boundary oxide must start all over again from a "time" zero. The time interval, st necessary to reach the critical size, $\delta a$, is given by,

$$
\delta t=\left(B / D_{g b}\right)(\delta a / \beta B)^{1 / n}
$$

where

B magnitude of the diffusion jumping vector or interatomic spacing

Dgb grain boundary diffusion coefficient

$\beta, \beta^{\prime}$ proportionality constants

$n$ positive exponent (less than unity)

The number of micro-ruptures during the holding period, $\Delta t_{H}$, is,

$$
m=\Delta t_{H} / \delta t=\left(\Delta t_{H} D_{g b} / B\right)(\beta B / \delta a)^{1 / n}
$$

$m$ is linearly proportional to the holding period and is inversely proportional to the frequency.

Fatigue crack growth per cycle is the sum of the micro-ruptures during the holding period,

$$
d a / d N=m \delta a
$$

From Eqs. (9) to (11) we obtain,

$$
d a / d N=\beta^{\prime} \Delta t_{H} D_{g b}(B / \delta a)^{l-n / n}=\beta^{\prime}\left(D_{g b} / f\right)(B / \delta a)^{1-n / n}
$$

Note that da/dN is inversely proportional to frequency, f. Figure 5 taken from Liu and Oshida (1986) illustrates the success the approach has had in correlating crack growth under high temperature environments. The experimental results shown in the figure were obtained from the open literature.

\section{ANISOTROPIC MATERIAL MODELING}

Pratt \& Whitney single crystal constitutive mode 1. Because of the exceptionally strong link between the cyclic deformation mechanisms in single crystal alloys and the fatigue crack initiation process, it was deemed advisable to develop both the cyclic constitutive and cyclic crack initiation life prediction models within a single program. Further. more, since single crystal alloys invariably require a protective coating for successful high-temperature applications, it was also necessary to develop a cyclic constitutive and life model for the coating systems. The constitutive models will be discussed in the following section.

A unified constitutive model has been formulated for PWA 1480 single crystal material and is currently in the final stages of development. The model uses the unified approach for computing all inelastic strain rather than the conventional approach of treating creep and plasticity separately. The model assumes that all inelastic behavior results from shear strains on each of the twelve octahedral and six cube slip systems and that the global inelastic strains are simply the sum of these slip systems strains. Slip system inelastic shear strain rates are governed by a set of viscoplastic equations which involve the slip system stresses and two evolutionary state variables The general form of the equation governing inelastic shear strain on the rth slip system as given by Swanson (1987) is,

$$
\dot{Y}_{r}=\frac{\left(\pi_{r}-\omega_{r}\right)\left|\pi_{r}-\omega_{r}\right|^{P-1}}{k^{P}}
$$

where

$\dot{Y}_{r}$ inelastic shear strain rate on the slip system

$\pi_{r}$ effective stress acting on the slip system

$\omega_{r}$ back stress acting on the slip system

$K \quad$ drag stress acting on the slip system

The model has been formulated to include several effects that have been reported to influence deformation. These include contributions from slip system stresses other than the Schmid shear stress, latent hardening due to simultaneous straining on all slip systems, and cross-slip from the octahedral to the cube slip systems.

A large body of isothermal constitutive data has been obtained at temperatures ranging from 427 to $1149{ }^{\circ} \mathrm{C}$ using uniaxial specimens oriented in the 
$\langle 001\rangle,\langle 011\rangle,\langle 111\rangle,\langle 123\rangle^{\circ}$ crystal orientations. The constitutive model constants have been determined from these isothermal tests. Figures 6 and 7 show the measured stress strain behavior and the calculated constitutive model behavior at $871^{\circ} \mathrm{C}$. The model is currently being evaluated against the stress-strain response of thermomechanical fatigue (TMF) tests which were conducted for life modeling. The single crystal constitutive model as well as the coating constitutive model reported below are compatible with a commercially available finite element computer code.

Pratt \& Whitney coating constitutive model. Thermomechanical fatique (TMF) cracks in turbine airfoils of PWA 1480 material generally originate from a coating crack. Thus, for airfoil life prediction, it is important to model the coating mechanical behavior as well as that of the PWA 1480. In this program, viscoplastic constitutive models are being developed for two fundamentally different coating types which are commonly used in gas turbines to provide oxidation protection: (1) a plasma sprayed NiCoCrAlY overlay coating, and (2) a pack-cementation-applied NiAl diffusion coating.

The isotropic formulation of Walker (1981) was chosen as the overlay coating constitutive model, based on its ability to reproduce isothermal and thermomechanical hysteres is loop data reported by Swanson et a1. (1987). The predicted overlay coating response of an out-of-phase thermomechanical cycle is compared to data in Fig. 8. For these purposes, solid cylindrical specimens of coating material were cut from a billet prepared by hot isostatic pressing of material powder. The aluminide diffusion coating constitutive model is currently under development, and will be more difficult to determine owing to the fact that it will be impossible to make solid specimens of stand-alone coating material.

Cyclic Crack Initiation

Directionally cast, anisotropic, nickel-base superalloys (particularly single crystals) exhibit greater creep-fatigue resistance than their conventionally cast polycrystalline counterparts. To take full advantage of these improved material properties, however, requires the development of accurate cyclic constitutive and life prediction models for these highly directional alloys. Direct modification of polycrystalline behavior models is inadequate, and a new approach that recognizes the micromechanisms of crystal response is necessary. Unfortunately, the program was able to address only the crack initiation aspects of single crystal superalloys. Cyclic crack growth life prediction modeling must await future efforts.

Pratt \& Whitney coating and single crystal iffe prediction model. Generally, all coated PWA 1480 orientations (i.e., $\langle 001\rangle,\langle 011\rangle,\langle 111\rangle$, and $\langle 123\rangle)$ which were tested in thermomechanical fatigue initiated cracks in the metal at sites where coating cracking had occurred. Isothermal tests of coated $\langle 001\rangle$ PWA 1480 also typically initiated cracks first in the coating layer. However, many coated non- $\langle 001\rangle$ isothermal fatigue tests initiated cracks underneath the specimen outer surface in either the PWA 1480 or the coating/PWA 1480 interfacial region. Initiation occurred predominately at porosity sites.

The following life prediction approach was developed to account for the observed specimen cracking modes,

$$
N_{f}=N_{C}+N_{S C}+N_{S P}
$$

or

$$
N_{f}=N_{S i}+N_{S p}
$$

whichever is the smallest.

where

$\mathrm{N}_{C}$ cycles to initiate a crack through the coating

$N_{S C}$ cycles for coating initiated crack to penetrate a small distance into the substrate

$\mathrm{N}_{5}$ i cycles to initiate a substrate crack due to macroscopic slip, oxidation effects, or defects

$\mathrm{N}_{\text {sp }}$ cycles to propagate substrate crack to failure

$N_{f}$ total cycles to fail specimen or component

The following modified tensile hysteretic energy model was developed for the overlay coating,

$$
N_{c}=C\left(\Delta w_{t}\right)^{-b_{v} m}
$$

where

$$
v=\frac{1}{\sum_{c y c l e} \frac{r\left(T_{i}\right)}{r\left(T_{0}\right)} t_{1}-D_{0}} ; v \leq 1.0
$$

$r(T) \quad r_{0} \exp (-Q / T)$ temperature- and time-dependent damage rate

$\Delta W_{t} \quad$ tensile hysteretic energy, $N-m / m^{3}\left(i n-l b f / i n .{ }^{3}\right)$

$T_{i}$ individual temperature levels in the the cycle, $K\left({ }^{\circ} R\right)$

$t_{i}$ time (min) at $T_{j}$, including 100 percent of tensile hold and 30 percent of compressive hold times in the cycle, if any

To threshold temperature for temperature dependent damage, assumed to be $1088 \mathrm{~K}\left(1960^{\circ} \mathrm{R}\right)$

$D_{0} \quad$ "incubation damage"

Q effective activation energy for temperatureand time-dependent damage.

The term, $v$, is an extension of the Ostergren (1976) time-dependent damage frequency term. As used herein, it includes both temperature- and time-dependent damage functions to model thermally activated processes.

Model constants were determined from isothermal tests conducted at $427,760,927$, and $1038{ }^{\circ} \mathrm{C}(800$, 1400,1700 , and $\left.1900^{\circ} \mathrm{F}\right)$. Coating hysteres is loops were predicted using the PWA 286 constitutive model incorporated into a one-dimensional model. This model determines the stress-strain of the substrate and coating by imposing an equivalent displacement history. Differences in coefficients of thermal expansion are included in the model.

The model unifies isothermal and TMF predicted lives within a factor of about 2.5, as seen in Fig. 9. Generally, the worst predicted test lives were limited to $1149{ }^{\circ} \mathrm{C}\left(2100^{\circ} \mathrm{F}\right)$ maximum temperature TMF tests.

$$
\begin{array}{r}
\text { ORIGINAT, PACE IS } \\
\text { OF :' UTYY }
\end{array}
$$


Prediction of these test results should improve when $1149^{\circ} \mathrm{C}\left(2100^{\circ} \mathrm{F}\right)$ isothermal tests are included in the data set used to determine model constants.

Additional model modification will be necessary to include the effect of biaxial coating loads introduced by the thermal growth mismatch between the coating and the substrate during uniaxial TMF tests and engine transients.

PWA 273 aluminide coating and PWA 1480 crack initiation model development for calculating $N_{S C}$. $N_{s o}$, and $N_{s i}$ is currently in process. At present, based on isothermal fatigue correlations, the most promising candidate models for these materials are a iso derived from an approach based on hysteretic energy.

\section{CONCLUDING REMARKS}

In conclusion, we would like to emphasize that significant accomplishments have been achieved in the fatigue and fracture arena through the atmosphere created by the HOST Project. We are now much better able to deal with durability enhancement in the aeronautical propulsion industry through theoretical, analytical, and experimental approaches. Given the ability to complete the tasks we have started, we expect to reap even greater rewards in the near future. be low:

The major accomplishments to-date are summarized

1. An advanced high-temperature fatigue and structures research laboratory has been implemented at the NASA Lewis.

2. Two new crack initiation life prediction methods have been developed for application to complex creep-fatigue loading of nominally isotropic superalloys a high temperatures.

3. Cyclic constitutive models for oxidation protective coatings and for highly anisotropic single crystal turbine blade alloys have been developed and verified.

4. A preliminary cyclic crack initiation life prediction model for coated single crystal superalloys has been proposed and is undergoing continued evaluation. The model utilizes tensile hysteretic energy and frequency as primary variables.

5. Two high temperature cyclic crack growth life prediction madels have been proposed: micromechanistic and phenomenological engineering approaches have been taken. The micromechanistic approach is based upon oxidation interactions with mechanical deformation at the crack tip, while the engineering approach has its origins in the use of Path-Independent Integrals to describe the necessary fracture mechanics parameters.

\section{REFERENCES}

Ainsworth, R.A., Neale, B.K., and Price, R.H., 1978 , "Fracture Behavior in the Presence of Thermal Strains," Tolerance of Flaws in Pressurized Components, Institution of Mechanical Engineers, London, pp. $171-178$.
Atluri, S.N., 1982, "Path-Independent Integrals in Finite Elasticity and Inelasticity, with Body Forces, Inertia, and Arbitrary Crack-Face Conditions," Engineering Fracture Mechanics, Vol. 16, No. 3 , po. 341-364.

Bartolotta, P.A. and McGaw, M.A., 1987, "A High Temperature Fatigue and Structures Testing Facility," NASA TM-100151.

Blackburn, W.S., Jackson, A.D., and Hellen, T.K., 1977, "An Integral Associated with the State of a Crack Tip in a Nonelastic Material," International Journal of Fracture, Vol. 13, No. 2, pp. 183-200.

Halford, G.R., Saltsman, J.F., and Hirschberg, M.H., 1977, "Ductility Normalized-Strainrange Partitioning Life Relations for Creep-Fatigue Life Prediction " Environmental Degradation of Engineering Materials, M.R. Louthan and R.P. McNitt, eds., Virginia Tech. Printing Dept., V.P.I. and State University, Blacksburg, VA, pp. 599-612. (NASA TM-73737).

Halford, G.R. and Saltsman, J.F., 1983, "Strainrange Partitioning - A Total Strainrange Version, "Advances in Life Prediction Methods, D.A. Woodford and J.R. Whitehead, eds., ASME, New York, pp. 17-26.

Hirschberg, M.H. and Halford, G.R., "Use of Strainrange Partitioning to Predict High-Temperature LowCycle Fatique Life," NASA TN D-8072, 1976.

Kim, K.S., 1988, "A Review of Path-Independent Integrals in Elastic-Plastic Fracture Mechanics," Fracture Mechanics: 18th National Symposium, ASTM STP-945, ASTM, Philadelphia, PA, In Press. (See also NASA CR-174956).

Kishimoto, K., Aoki, S., and Sakata, M., 1980, "On the Path Independent Integral-J," Engineering Fracture Mechanics, Vol. 13, No. 4, pp. 841-850.

Lindholm, U.S., Chan, K.S., Bodner, S.R., Weber, R.M., Walker, K.P., and Cassenti, B.N., 1984 "Constitutive Modeling for Isotropic Materials (HOST)," NASA CR-174718.

Liu, H.W. and Oshida, Y., 1986, "Grain Boundary Oxidation and Fatigue Crack Growth at Elevated Temperatures," Theoretical and Applied Fracture Mechanics, Vol. 6, No. 2, pp. 85-94.

Manson, S.S., Halford, G.R., and Nachtigall, A.J., 1975, "Separation of the Strain Components for Use in Strainrange Partitioning, "Advances in Design for Elevated Temperature Environment, S.Y. Zamrik and R.I. Jetter, eds., ASME, New York, pp. 17-28.

McGaw, M.A. and Bartalotta, P.A., 1987, "A High Temperature Fatigue and Structures Testing Facility, " 4th Annual Hostile Environments and High Temperature Measurements Conference Proceedings, Society for Experimental Mechanics, Bethel, CT, pp. 12-29. (See also, NASA TM-100151).

Moreno, V., 1983, "Creep Fatigue Life Prediction for Engine Hot Section Materials (Isotropic). "NASA CR-168228.

Moreno, V., Nissley, D.M., and Liu, L.S., 1985 , "Creep Fatigue Life Prediction for Engine Hot Section Materials (Isotropic)," NASA CR-174844. 
Moreno, V., Nissley, D.M., Halford, G.R., and Saltsman, J.F., 1985, "Application of Two CreepFatigue Life Models for the Prediction of Elevated Temperature Crack Initiation of a Nickel-Base Alloy," AIAA Paper 85-1420.

Nelson, R.S., Schoendorf, J.F., and Lin, L.S., 1986 , "Creep Fatigue Life Prediction for Engine Hot Section Materials (Isotropic)," NASA CR-179550.

Oshida, Y. and Liu, H.W., 1988, "Grain Boundary Oxidation and an Analysis of the Effects of Oxidation on Fatigue Crack Nucleation Life," Low Cycle Fatigue-Oirections for the Future, ASTM STP-942, ASTM,

Philadelphid, PA, pp. 1199-1217.

Ostergren, W.J., 1976, "A Damage Function and Associated Failure Equations for Predicting Hold Time and Frequency Effects in Elevated-Temperature, Low-Cycle Fatigue," Journal of Testing and Evaluation, Vol.4, No. $5, p p, 327-339$
Ramaswamy, V.G., Van Stone, R.H., Dame, L.T., and Laflen, J.H., 1985, "Constitutive Modeling for Isotropic Materials," NASA CR-175004.

Saltsman, J.F. and Halford, G.R., 1988, "An Update of the Total Strain Version of SRP." Low Cycle Fatigue--Directions for the Future, ASTM STP-942, ASTM, Philadelphia, PA, pp. 329-34l.

Swanson, G.A., Linask, I., Nissley, D.M. Norris, P.P., Meyer, T.G., and Walker, K.P., 1987 , "Life Prediction and Constitutive Models for Engine Hot Section Anisotropic Materials," NASA CR-179594.

Tada, H., Paris, P.C., and Irwin, G.R., 1973, The Stress Analysis of Cracks Handbook, Del Research Corporation, Hellertown, PA.

Walker, K.P., 1981, "Research and Development Programs for Nonlinear Structural Modeling with Advanced Time-Temperature Dependent Constitutive Relationships," NASA CR-165533.

TABLE I. - HOST FATIGUE AND FRACTURE PROGRAMS

- NAS3-23288, Pratt \& Whitney (R.S. Nelson) Creep-Fatigue Crack Initiation--Isotropic

- NAS3-23940, General Electric (J.J. Laflen) Elevated Temperature Crack Growth--Isotropic

- NAS3-23939, Pratt \& Whitney (G.A. Swanson) Life Prediction/Constitutive Modeling--Anisotropic

- NAG3-348, Syracuse University (H.W. Liu) Crack Growth Mechanisms--Isotropic

- Lewis (M.A. McGaw) High-Temperature Fatigue and Structures Laboratory 


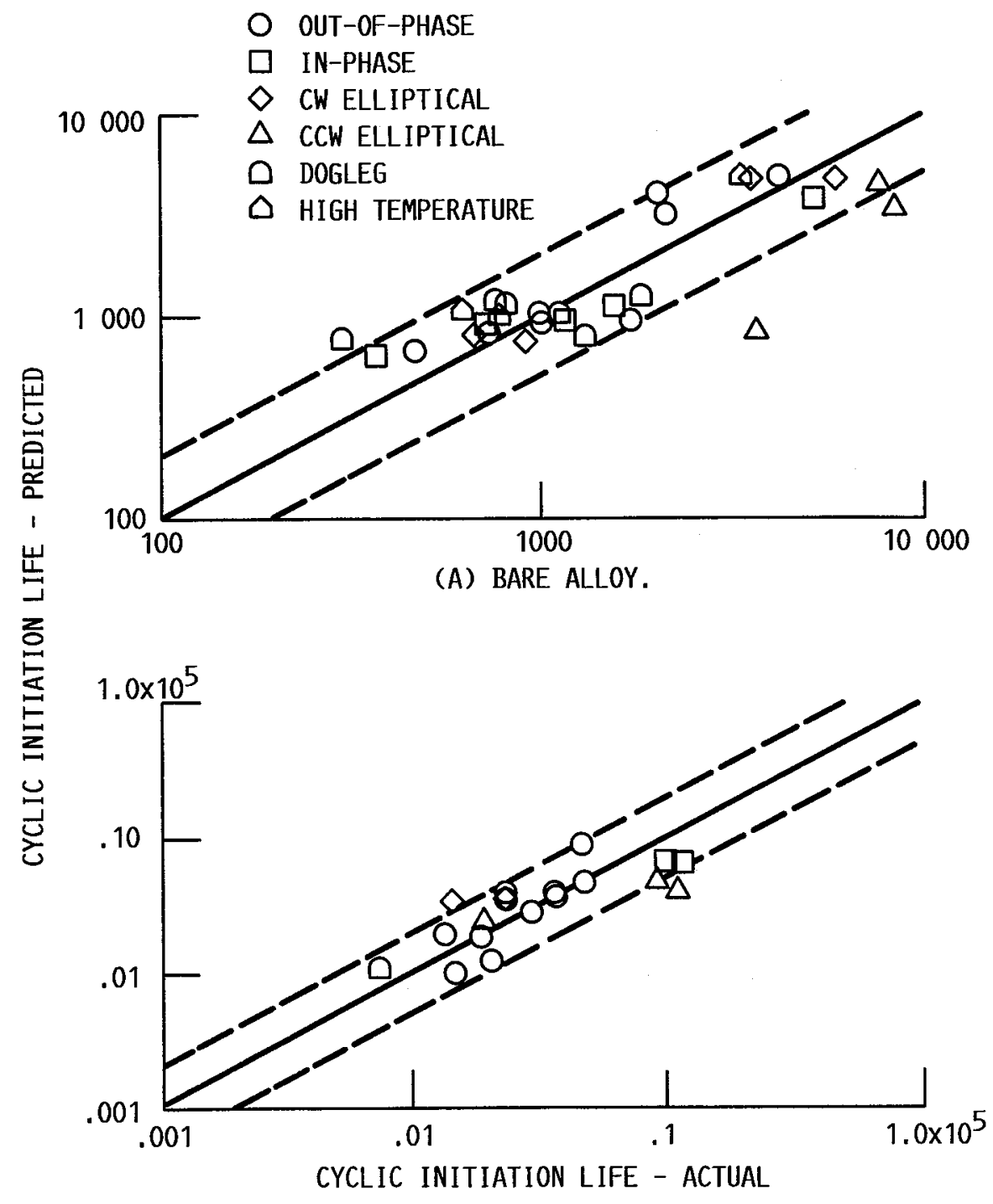

(B) COATED ALLOY.

FIGURE 1. - APPLICATION OF PRELIMINARY CDA MODEL TO TMF LIFE PREDICTION FOR THE CAST NICKEL-BASE ALLOY, PWA 1455 (B1900 + HF). AFTER MORENO (1986). 


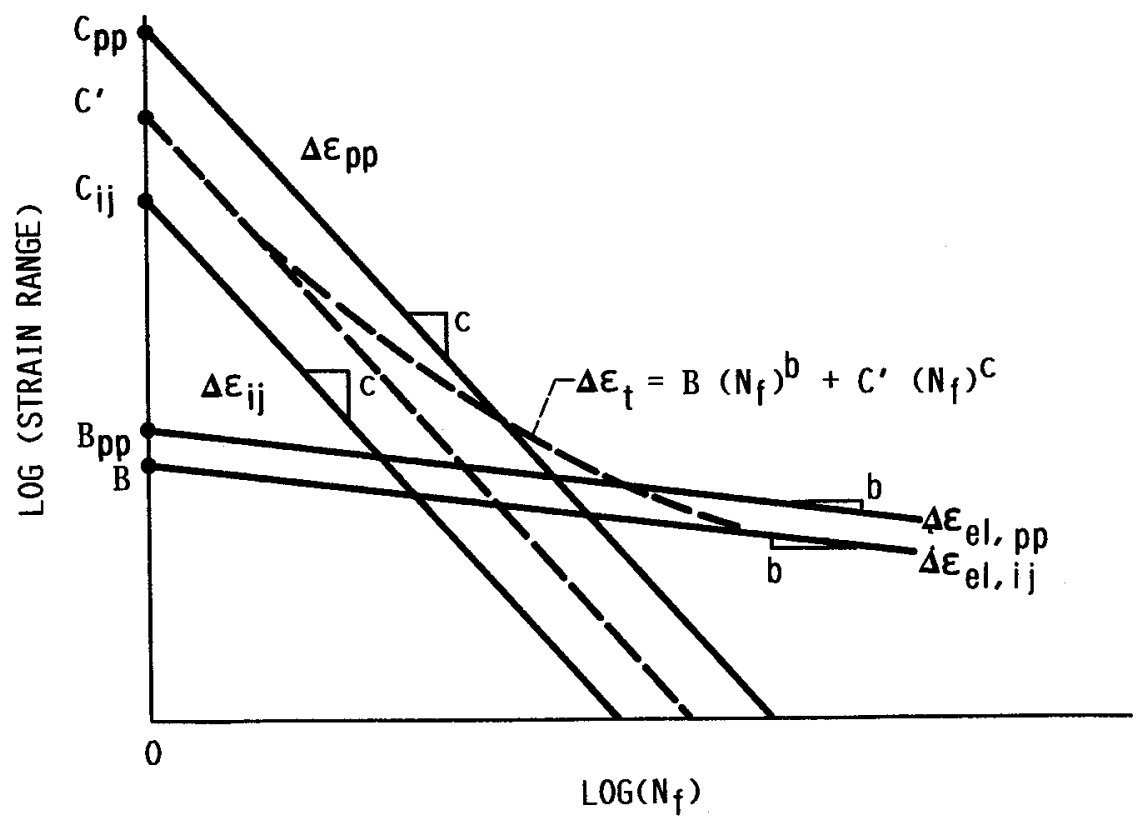

FIGURE 2. - SCHEMATIC REPRESENTATION OF TOTAL STRAINSTRAINRANGE PARTITIONING (TS-SRP). 


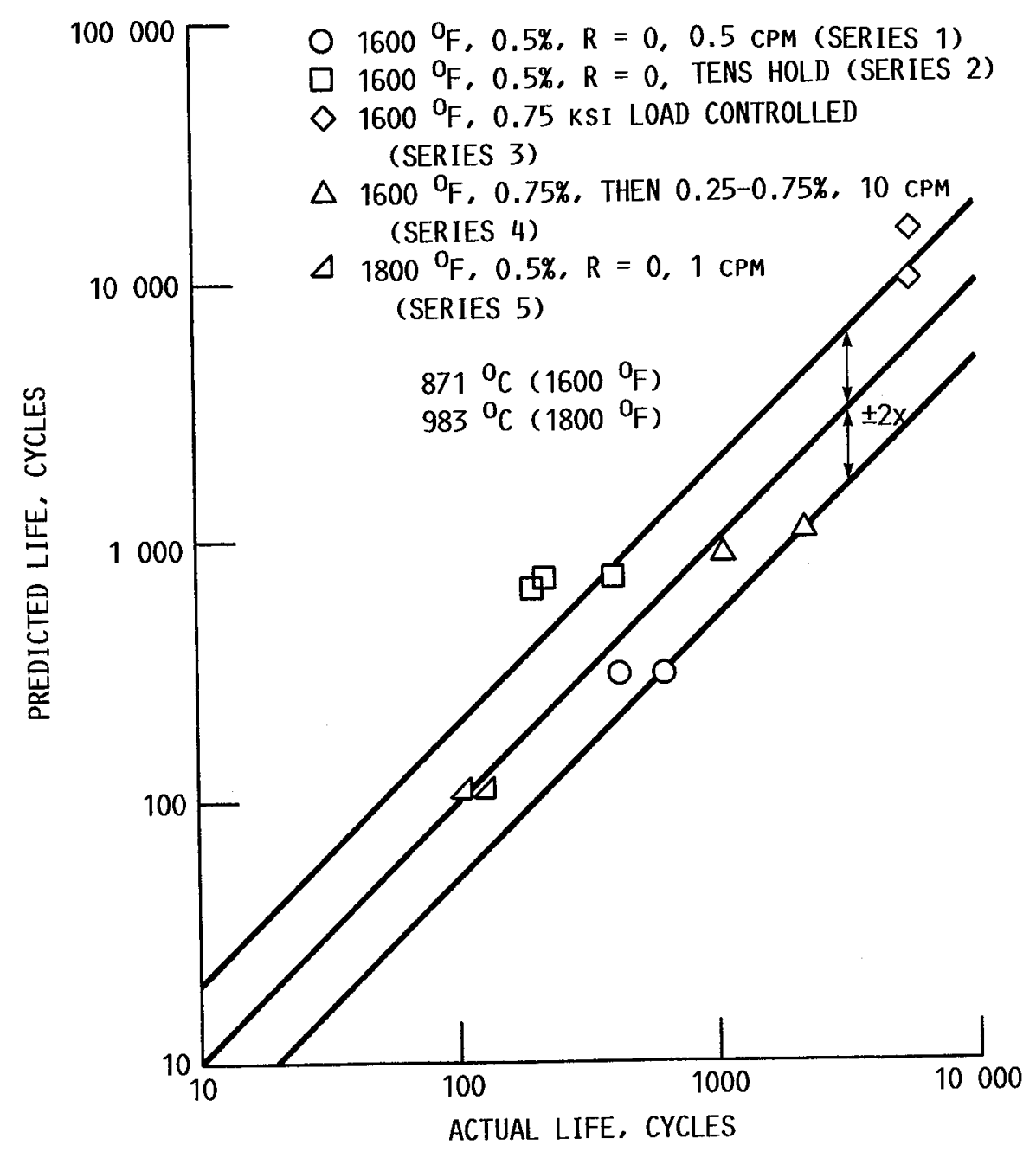

FIGURE 3. - PREDICTION OF COMPLEX VERIFICATION EXPERIMENTS USING TS-SRP, AFTER MORENO (1985). 


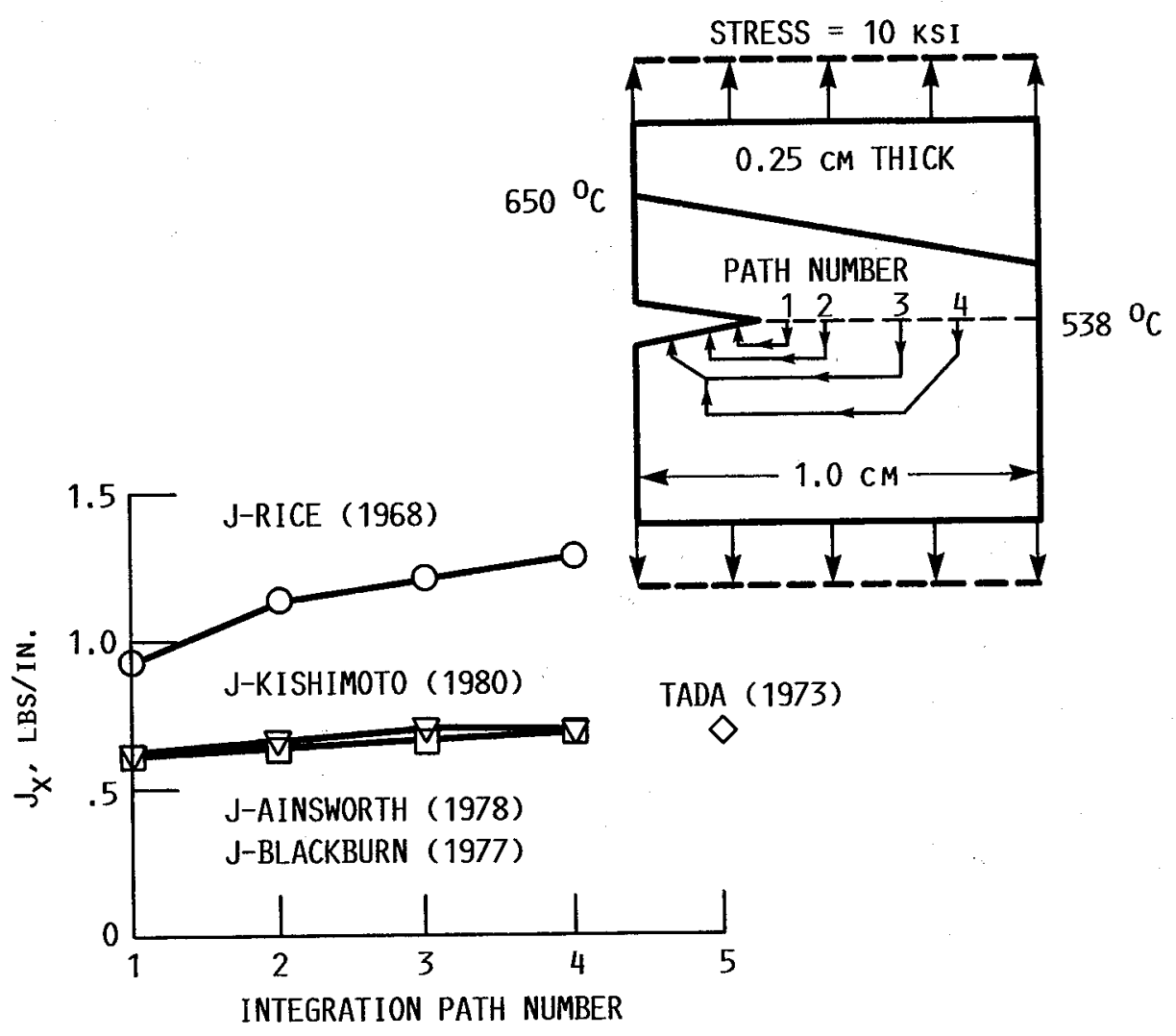

FIGURE 4. - EVALUATION OF PATH-INDEPENDENT INTEGRALS UNDER LINEAR TEMPERATURE GRADIENT IN SINGLE EDGE NOTCH SPECIMENS OF INCONEL 718, AFTER KIM AND ORANGE (1988). 


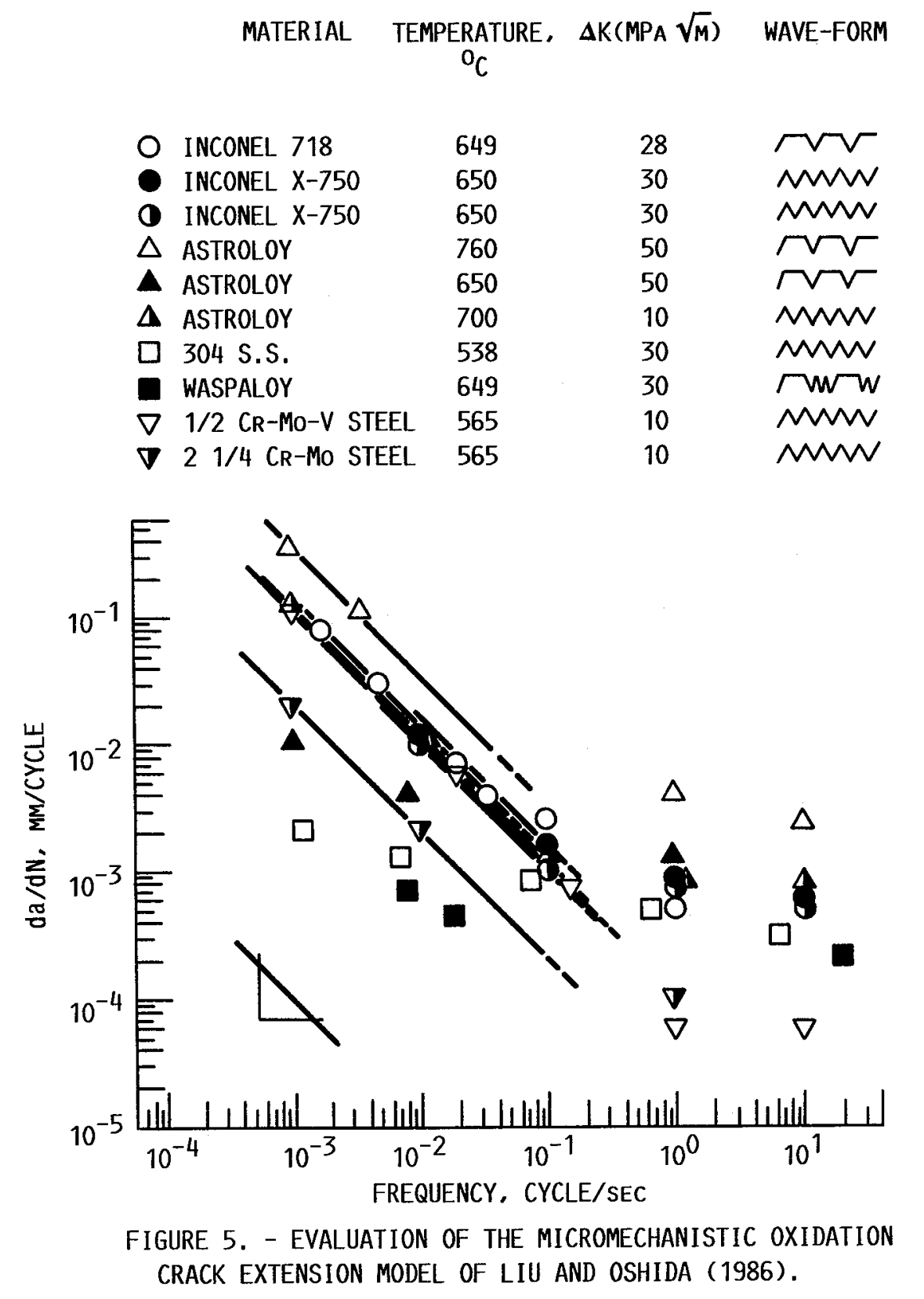




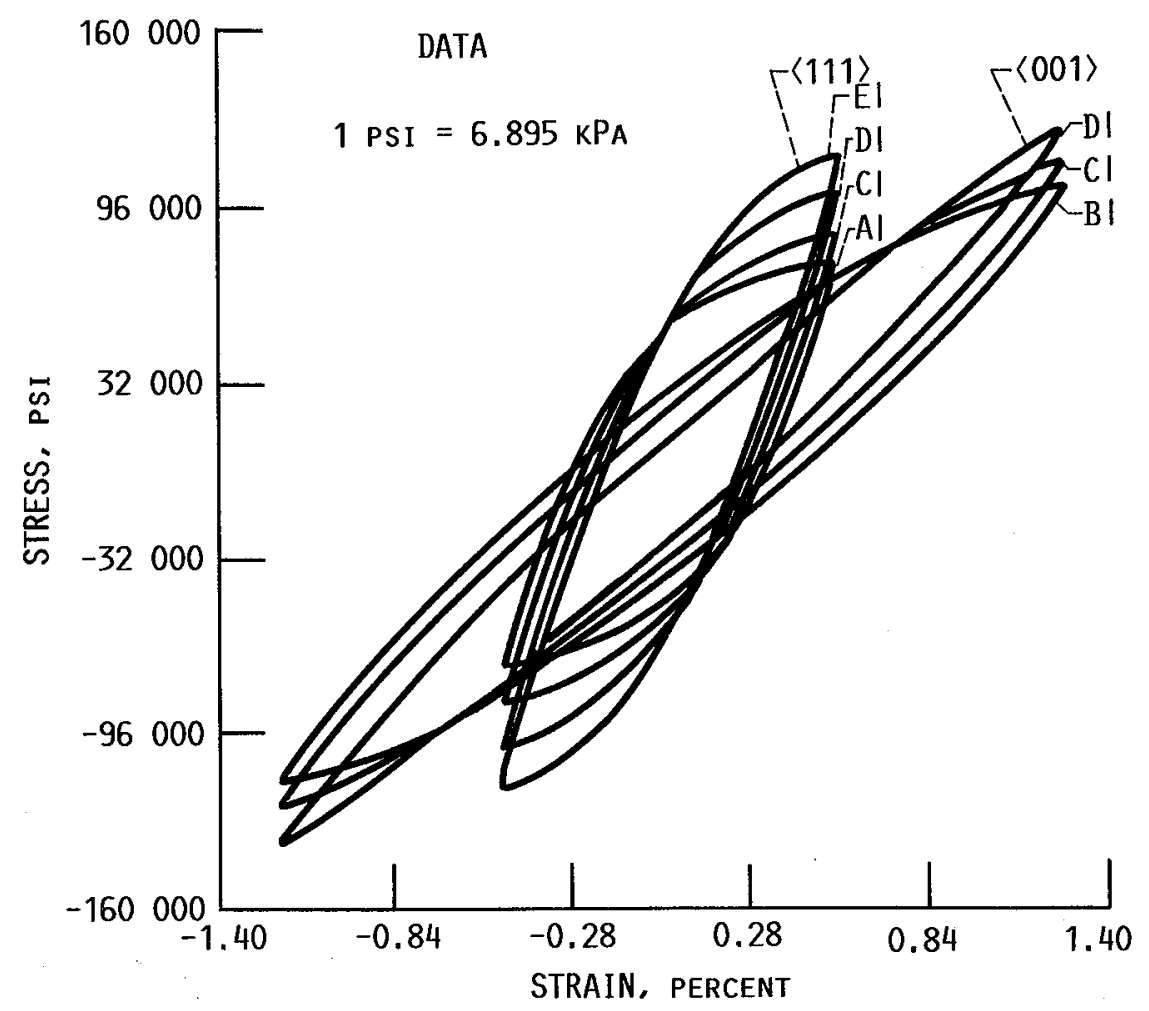

FIGURE 6. - EXPERIMENTAL LOOPS IN 〈001〉 AND 〈111〉 DIRECTIONS AT $871 \mathrm{C}\left(1600^{\circ} \mathrm{F}\right)$ AT STRAIN RATES OF: (A) $0.001 \%$ PER SECOND, (B) $0.0025 \%$ PER SECOND, (C) $0.01 \%$ PER SECOND, (D) $0.1 \%$ PER SECOND, AND (E) $0.5 \%$ PER SECOND. 


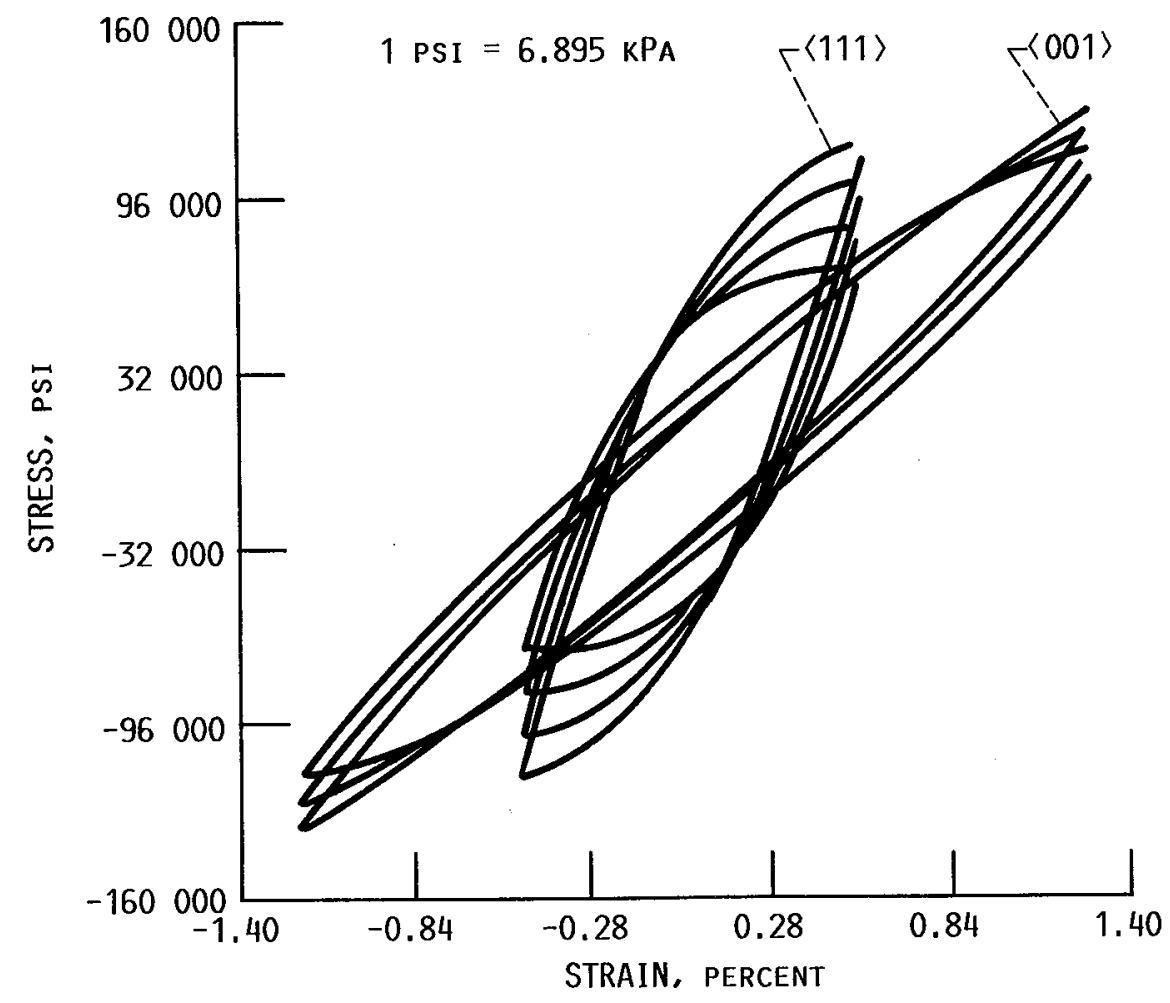

FIGURE 7. - MICRO MODEL WITH BOTH OCTAHEDRAL AND CUBE SLIP TERMS CORRELATED TO 〈111〉 AND 〈001〉 DATA.

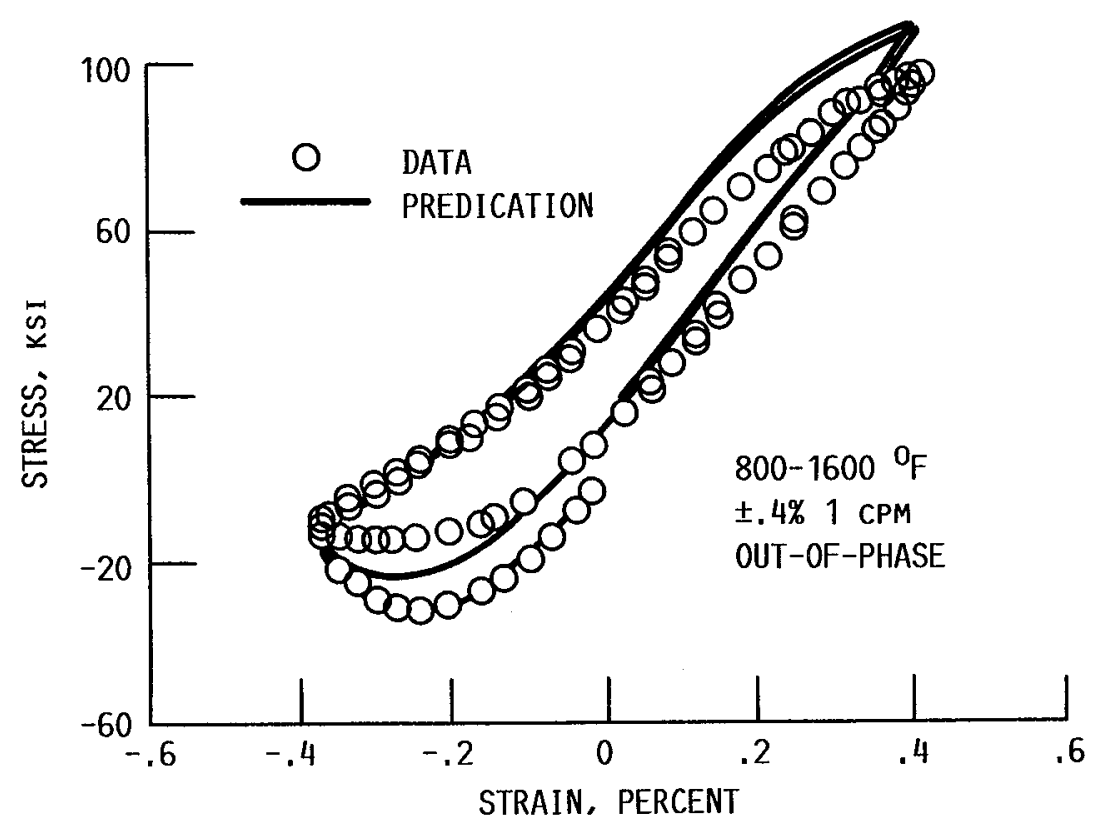

FIGURE 8. - OVERLAY COATING CONSTITUTIVE MODEL PREDICTION OF THERMAL MECHANICAL CYCLE AND COMPARISON WITH DATA. 


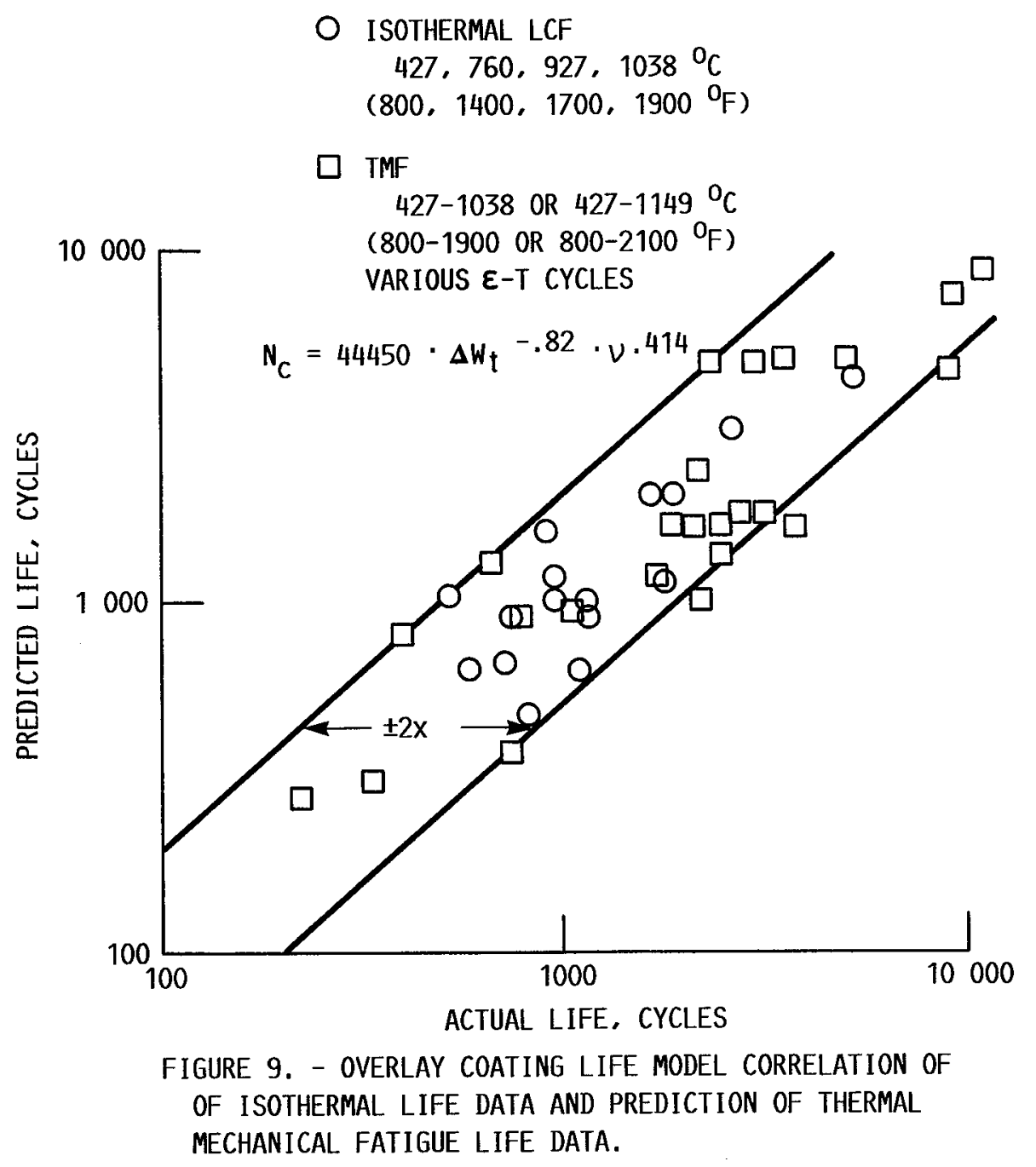




\begin{tabular}{|c|c|c|c|c|}
\hline \multicolumn{5}{|c|}{ Report Documentation Page } \\
\hline $\begin{array}{l}\text { 1. Report No. } \\
\text { NASA TM-100291 }\end{array}$ & \multicolumn{2}{|c|}{ 2. Government Accession No. } & \multicolumn{2}{|c|}{ 3. Recipient's Catalog No. } \\
\hline \multirow{2}{*}{\multicolumn{3}{|c|}{$\begin{array}{l}\text { 4. Title and Subtitle } \\
\text { Fatigue Life Prediction Modeling for Turbine } \\
\text { Hot Section Materials }\end{array}$}} & \multirow{2}{*}{\multicolumn{2}{|c|}{ 5. Report Date }} \\
\hline & & & & \\
\hline \multirow{2}{*}{\multicolumn{3}{|c|}{$\begin{array}{l}\text { 7. Author(s) } \\
\text { G.R. Halford, T.G. Meyer, R.S. Nelson, } \\
\text { D.M. Nissley, and G.A. Swanson }\end{array}$}} & \multicolumn{2}{|c|}{$\begin{array}{l}\text { 8. Performing Organization Report No. } \\
\text { E-3927 }\end{array}$} \\
\hline & & & \multicolumn{2}{|c|}{$\begin{array}{l}\text { 10. Work Unit No. } \\
506-63-1 \mathrm{~B}\end{array}$} \\
\hline \multirow{3}{*}{\multicolumn{3}{|c|}{$\begin{array}{l}\text { 9. Performing Organization Name and Address } \\
\text { National Aeronautics and Space Administration } \\
\text { Lewis Research Center } \\
\text { Cleveland, Ohio } 44135-3191\end{array}$}} & \multirow{2}{*}{\multicolumn{2}{|c|}{ 11. Contract or Grant No. }} \\
\hline & & & & \\
\hline & & & \multirow{2}{*}{\multicolumn{2}{|c|}{$\begin{array}{l}\text { 13. Type of Report and Period Covered } \\
\text { Technical Memorandum }\end{array}$}} \\
\hline \multirow{2}{*}{\multicolumn{3}{|c|}{$\begin{array}{l}\text { 12. Sponsoring Agency Name and Address } \\
\text { National Aeronautics and Space Administration } \\
\text { Washington, D.C. 20546-0001 }\end{array}$}} & & \\
\hline & & & \multicolumn{2}{|c|}{ 14. Sponsoring Agency Code } \\
\hline \multicolumn{5}{|l|}{ 15. Supplementary Notes } \\
\hline \multicolumn{5}{|c|}{$\begin{array}{l}\text { Prepared for the 33rd International Gas Turbine and Aeroengine Congress and Exposition sponsored by } \\
\text { the American Society of Mechanical Engineers, Amsterdam, The Netherlands, June 5-9, 1988. G.R. } \\
\text { Halford, NASA Lewis Research Center; T.G. Meyer, R.S. Nelson, D.M. Nissley, and G.A. Swanson, United } \\
\text { Technologies, Pratt \& Whitney, East Hartford, Connecticut 06i08. }\end{array}$} \\
\hline \multicolumn{5}{|c|}{ 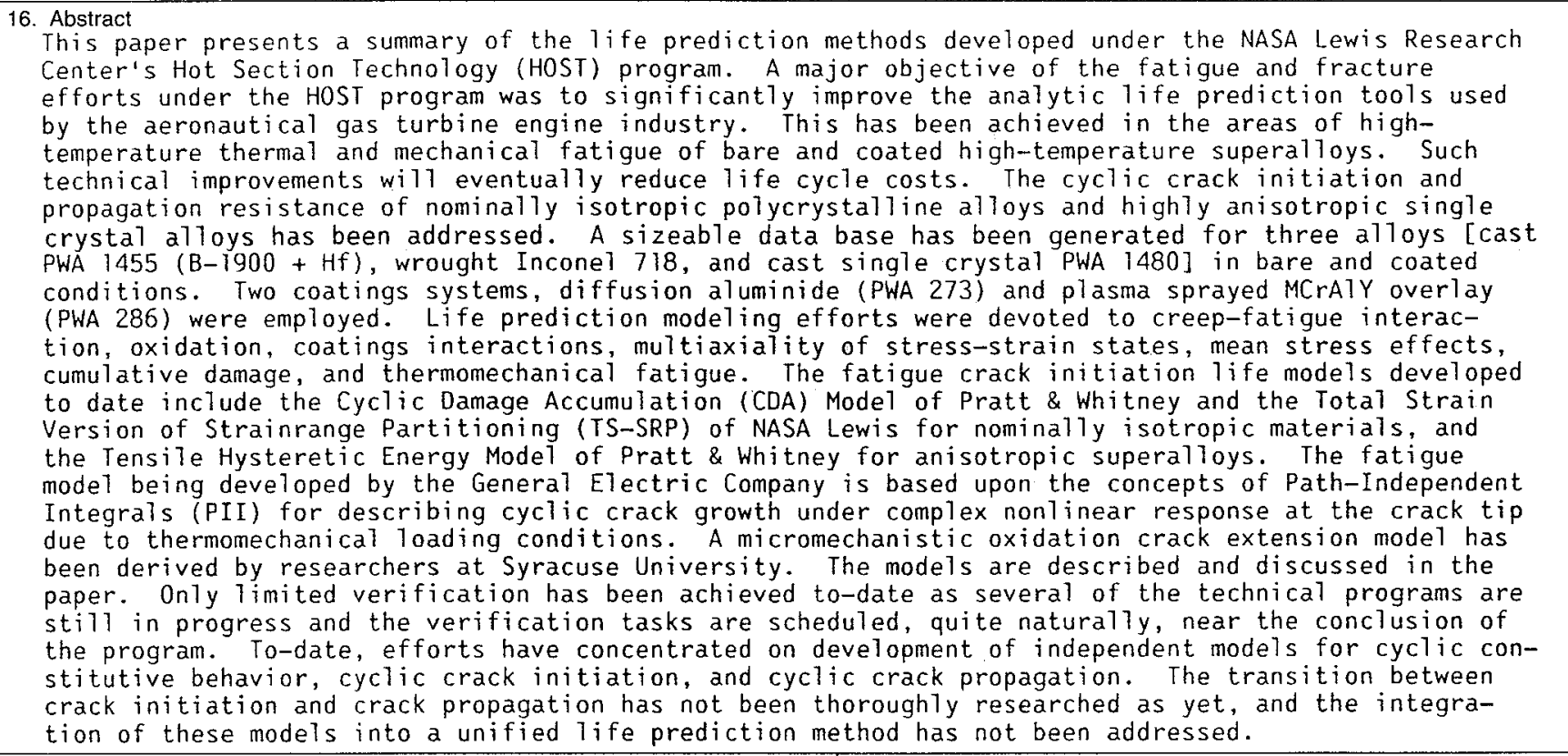 } \\
\hline \multicolumn{2}{|c|}{$\begin{array}{l}\text { 17. Key Words (Suggested by Author(s)) } \\
\text { Metal fatigue; Low-cycle fatigue; Thermal fatigue; } \\
\text { Thermomechanical fatigue; Creep fatigue; Creep; } \\
\text { Crack initiation; Crack propagation; Life predic- } \\
\text { tion; Oxidation; SuperalToys; Coatings; Single } \\
\text { crystal; Constitutive modeling; Strainrange } \\
\text { partitioning; Path-independent integrals }\end{array}$} & \multicolumn{3}{|c|}{$\begin{array}{l}\text { 18. Distribution Statement } \\
\text { Unclassified - Un } 1 \text { imited } \\
\text { Subject Category } 39\end{array}$} \\
\hline 19. Security Classif. (of this report) & Security Classif. (of this & & 21. No of pages & 22. Price* \\
\hline & & & & \\
\hline
\end{tabular}

